\title{
ULTRASONIC FATIGUE STRENGTH IN INCONEL 718
}

\author{
Q. Chen ${ }^{1}$, N. Kawagoishi ${ }^{1}$, K. Othubo ${ }^{1}$, E. Kondo ${ }^{1}$ \\ M. Sakai ${ }^{2}$, and T. Kizaki ${ }^{2}$ \\ ${ }^{1}$ Kagoshima University, Department of Mechanical Engineering \\ 1-21-40 Korimoto \\ Kagoshima 890-0065, Japan \\ ${ }^{2}$ Ono Sokki Co, Ltd., Sensor \& Application Division \\ 1-61-1 Hakusan, Midori-ku \\ Yokohama 226-0006, Japan
}

\begin{abstract}
The fatigue strength of a nickel-base superalloy, Inconel 718, was investigated at room temperature under an ultrasonic frequency $(19.5 \mathrm{kHz})$ loading in ambient air environment. The endurance $(S-N)$ data show that fatigue strength was enhanced at ultrasonic frequency as compared to those at conventional frequencies. Small crack initiation and propagation behavior was observed during the fatigue progress at both ultrasonic fatigue and conventional rotary bending fatigue. The effect of frequency on the fatigue fracture mechanism was examined from a microscopic viewpoint.
\end{abstract}




\section{Introduction}

The strength reliability of engineering structural materials employed in aerospace and nuclear industrial applications after exposing in service for more than 10 years or more has been questioned, because the traditional fatigue limits that were obtained under fatigue tests up to $10^{7}$ cycles are difficult to be ever used as criteria for the strength design of these materials. ${ }^{[1.2]}$ Therefore, the fatigue properties of materials in the life range beyond $10^{7}$ cycles are of much interests to machine designers and material engineers. However, investigation of fatigue properties at high cycle regime is extremely time consuming by using conventional fatigue testing method. In this case, ultrasonic testing method may be an effective choice for the possibility of time saving at ultrasonic frequency. Nevertheless, ultrasonic testing method can also be used to investigate the effect of frequency on high cycle fatigue properties, which is of great significance to the design and maintenance of machines and components operating at high speeds, such as jet engines and gas turbine engines. Unfortunately, information on ultrasonic fatigue of metals is far from abundance in contrast to the data available for conventional fatigue of metals and the nature of ultrasonic fracture has not been well understood. ${ }^{[3,4]}$ For example, frequency effect was reported in some metals and various interpretations such as internal friction and damping properties of materials as well as the slip-band formation were supposed responsible. ${ }^{[5,6]}$ However, an adequate theoretical explanation is not yet available because fatigue is a much complicated phenomenon and is easily influenced by both material and environmental factors.

The objective of the present study is, therefore, to investigate the fatigue strength and fracture mechanism of a nickel-base superalloy Inconel 718 under ultrasonic frequency fatigue at room temperature in order to examine the effect of frequency on small crack initiation and propagation properties in the alloy.

\section{Material and Experimental}

The material used was a nickel-base superalloy Inconel 718. The chemical composition (wt\%) of the alloy is $0.03 \mathrm{C}, 0.05 \mathrm{Si}, 0.06 \mathrm{Mn}, 0.008 \mathrm{P}, 0.002 \mathrm{~S}, 18.5 \mathrm{Cr}, 3.08 \mathrm{Mo}, 0.27 \mathrm{Co}, 0.02 \mathrm{Cu}, 0.55 \mathrm{Al}$, $0.96 \mathrm{Ti}, 19.18 \mathrm{Fe}, 0.004 \mathrm{~B}, 5.03 \mathrm{Nb}$ and $\mathrm{Ta}$, and remainder $\mathrm{Ni}$. The alloy was solution treated at $982^{\circ}$ for $1 \mathrm{~h}$, water quenched, then aged at $720^{\circ}$ for $8 \mathrm{~h}$, furnace cooled to $621^{\circ}$ and aged at $621^{\circ}$ for $8 \mathrm{~h}$ followed by air-cooling. The microstructure after heat treatment is presented in Figure 1. The mean grain size was approximately $9 \mu \mathrm{m}$. The mechanical properties at room temperature were $1320 \mathrm{MPa}$ of $0.2 \%$ proof stress and $1460 \mathrm{MPa}$ of ultimate strength.

Ultrasonic fatigue specimen, as shown in Figure 2a, was designed to generate a longitudinal resonance vibration at a frequency of $19.5 \mathrm{kHz}$, leading to a sinusoidal cyclic loading passed 
onto the specimen with the maximum strain or stress amplitude produced in the center of the specimen and the maximum displacement at its end. Conventional rotary bending fatigue specimen, as shown in Figure $2 \mathrm{~b}$, was also employed to investigate the influence of loading frequency on the fatigue strength and fracture mechanism.

(a)

(b)

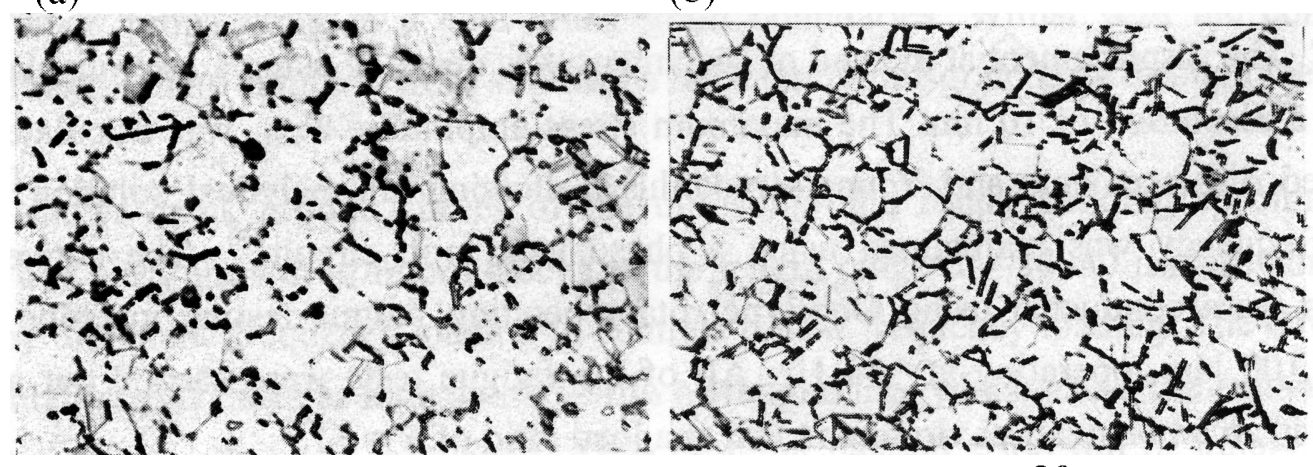

$20 \mu \mathrm{m}$

Figure 1: Microstructure of Inconel 718. (a) Longitudal section; (b) cross section.

a.

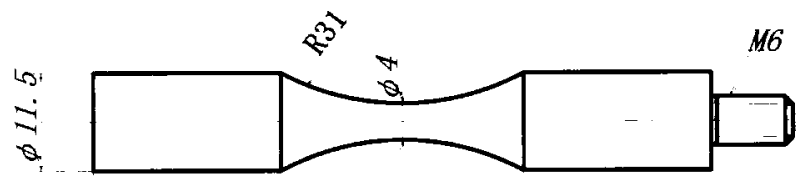

29. 5

68.9

b.

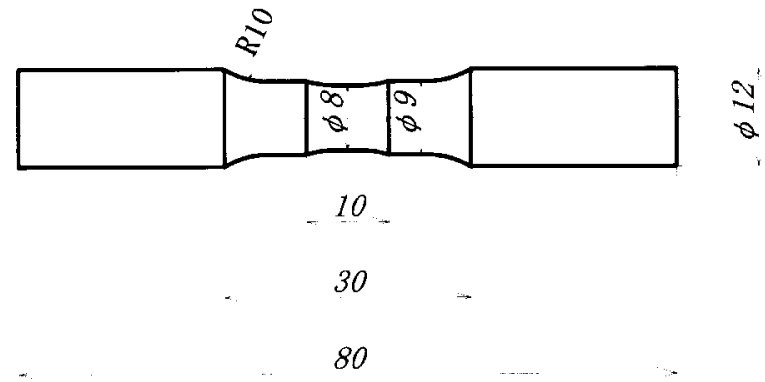

Figure 2: Geometry of (a) ultrasonic frequency and (b) rotary bending fatigue specimens. Dimensions in $\mathrm{mm}$.

Prior to fatigue testing, all the specimens were electro-polished to remove surface layer by $\sim 20$ $\mu \mathrm{m}$ (i.e., $40 \mathrm{~mm}$ in diameter). The observation of fatigue damage and the measurement of crack length were conducted directly under a scanning electron microscope (SEM) or under an optical microscope using plastic replicas. The crack length, $l$, was measured along the circumferential 
direction on the specimen surface. The stress value referred to is either the maximum stress amplitude, $\sigma_{\max }$, for tests under ultrasonic frequency loading or the nominal stress amplitude, $\sigma_{\mathrm{a}}$, for tests under rotary bending loading, at the minimum cross section of the specimens.

Ultrasonic fatigue tests were performed in a pulsed manner with pulse length of $25-50 \mathrm{~ms}$ and pauses between 1000-2000 ms. Temperature of in the center of specimens was controlled below $50^{\circ} \mathrm{C}$. The displacement at the end of specimens was detected using a laser displacement gauge with a resolution of $10 \mathrm{~nm}$. The maximum stress amplitude, $\sigma_{\max }$, was calculated from the measured displacements and Young's modulus, following an analytical solution. ${ }^{[7]}$ The resonance frequency was maintained using a phase lock loop circuit. ${ }^{[8]}$ The conventional fatigue tests were conducted using Ono-type rotary bending fatigue testing machine with a capacity of $100 \mathrm{Nm}$, operating at $\sim 55 \mathrm{~Hz}$. All of the fatigue tests were carried out at room temperature in an ambient air environment and at a load ratio of $R=-1$.

\section{Results and Discussion}

\section{Endurance $(S-N)$ curves}

Figure 3 shows the endurance $(S-N)$ data. To investigate the effect of high frequency on fatigue strength, data obtained under rotary bending fatigue in the present study and those reported by Korth and Smolik, ${ }^{[9]}$ are also included. Fatigue strength is enhanced under ultrasonic fatigue, especially in the life range below $10^{6}$ cycles. In the life range beyond $10^{7}$ cycles, however, this increase in fatigue strength becomes small. A limiting stress, $\sim 530 \mathrm{MPa}$, exists in the life range up to $10^{9}$ cycles under ultrasonic fatigue.

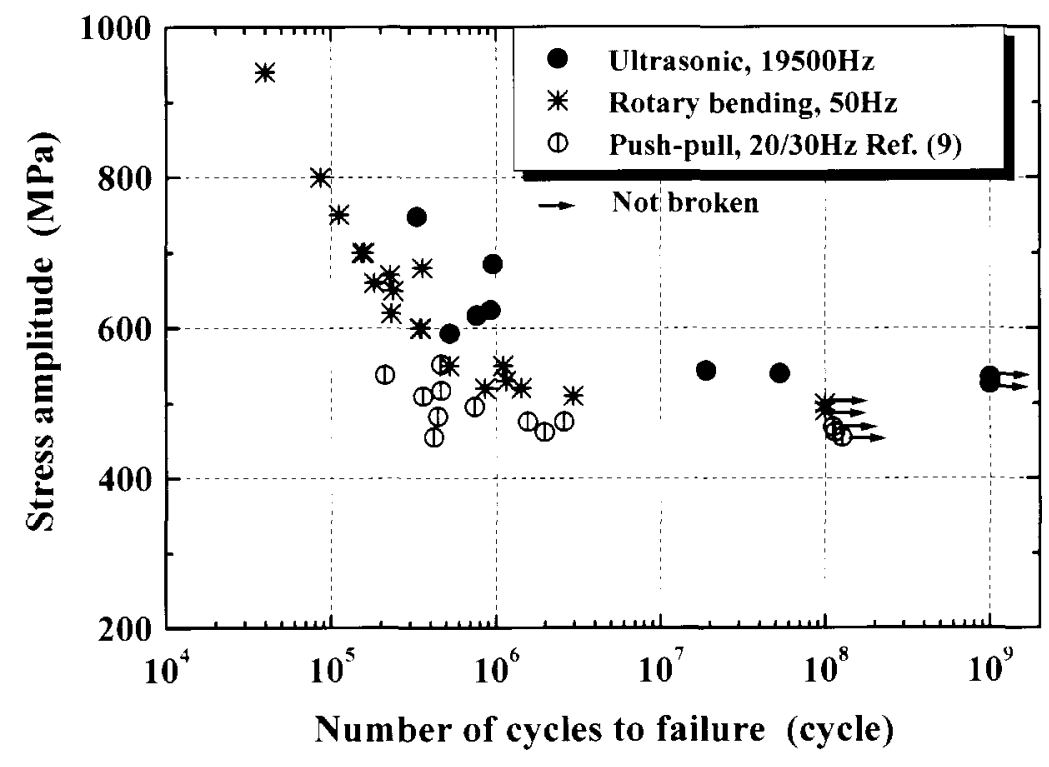

Figure 3: $S-N$ data of ultrasonic frequency and conventional fatigue specimens. 
Sequence replica micrographs of the ultrasonically fatigued and rotary bending fatigued specimens are shown in Figures 4 and 5, respectively. In case of ultrasonic fatigue, slip bands nucleate near grain boundary (Figure $4 \mathrm{~b}$ ) and degenerate into small cracks, which coalesce into a macro crack propagating in a path along grain boundaries. Whilst with the conventional fatigue, cracks initiate similarly from slip bands but extend transgranularly through the metal.

Figure 6 shows crack growth curves of the ultrasonic and rotary bending specimens. Both initiation and early growth of micro cracks in the length range of $-30-50 \mu \mathrm{m}$ are considerably delayed by ultrasonic frequency loading in contrast to low frequency loading. The development of such small cracks takes as high as $\sim 80-90 \%$ of fatigue life, which cause the enhancement of fatigue strength at ultrasonic frequency. After growing beyond $-500 \mu \mathrm{m}$ or longer, the small cracks extend faster leading to a premature catastrophic failure under ultrasonic frequency fatigue. The striking different growth behavior of small cracks under ultrasonic frequency loading can scarcely over-emphasized and the effect of frequency on the fracture mechanism must be investigated.
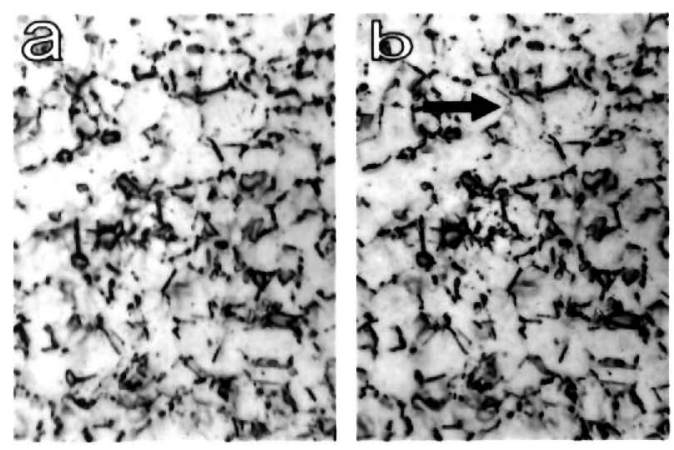

$(\leftrightarrow:$ axial direction)

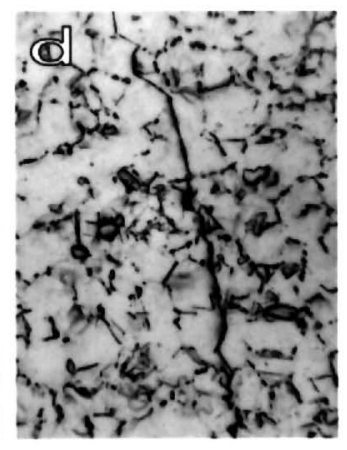

$50 \mu \mathrm{m}$

Figure 4: Optical micrographs of an ultrasonically fatigued specimen ( $\left.\sigma_{\max }=700 \mathrm{MPa}\right)$ after (a) 0 ; (b) $1.4 \times 10^{5}$; (c) $6.9 \times 10^{5}$; and (d) $9.5 \times 10^{5}$ cycles, respectively.
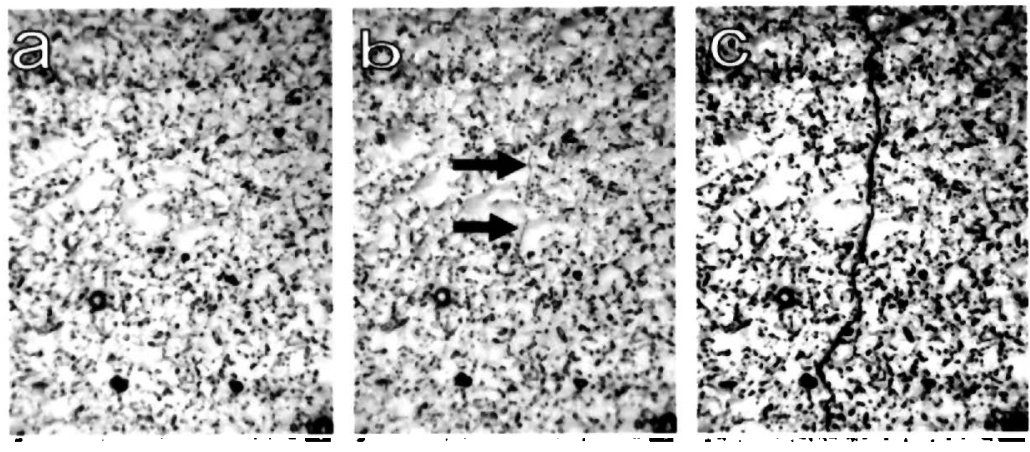

$(\leftrightarrow:$ axial direction)

$50 \mu \mathrm{m}$

Figure 5: Optical micrographs of a conventionally fatigued specimen $\left(\sigma_{\mathrm{a}}=700 \mathrm{MPa}\right)$ after (a) 0 ; (b) $4 \times 10^{4}$; and (c) $9 \times 10^{4}$ cycles, respectively. 

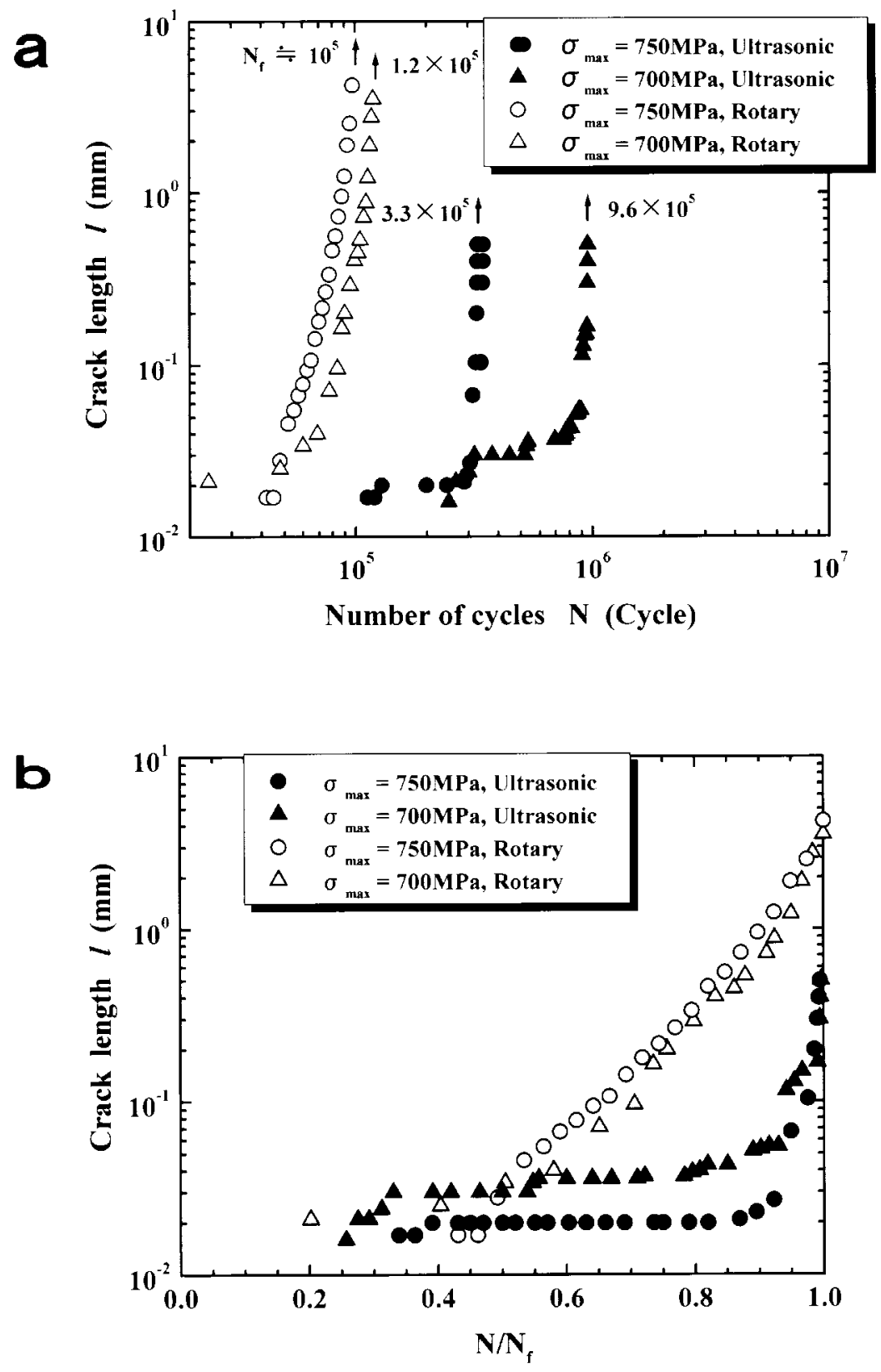

Figure 6: Crack growth curves of the ultrasonic and rotary bending fatigue specimens. (a) $l$ versus $N$; (b) $l$ versus life ratio $N / N_{\mathrm{f}}$.

\section{Effect of frequency on fatigue fracture mechanism}

Typical fracture morphologies of ultrasonically and conventionally fatigued specimens under high stress levels are demonstrated in Figure 7. In each of the specimens, cracks initiated from slip bands and the effect of frequency is hardly recognized, corroborating with the surface observation of Figures 4 and 5. Striations that were often observed on the fracture surface of conventional fatigued specimens, are not clear on the fracture surface of ultrasonic fatigued 
specimen. Instead, the fracture surface of ultrasonic fatigued specimen shows promptly the presence of intense slip bands and the fractographic feature is more brittle predominated, in contrast to the tensile fracture surface of the conventionally fatigued specimen (Figure $7 \mathrm{~b}$ ). The difference in the fracture surfaces indicates that fracture mechanism under ultrasonic frequency fatigue is different from that under conventionally low frequency fatigue. Considering the considerable delay in the initiation and early propagation of small cracks as well as the catastrophic rupture occurred at ultrasonic frequency loading (Figure 6), it is necessary to investigate the growth behavior of small cracks, especially in the surface length range of $\sim 20-1000 \mu \mathrm{m}$, at their different growth stages under ultrasonic frequency.
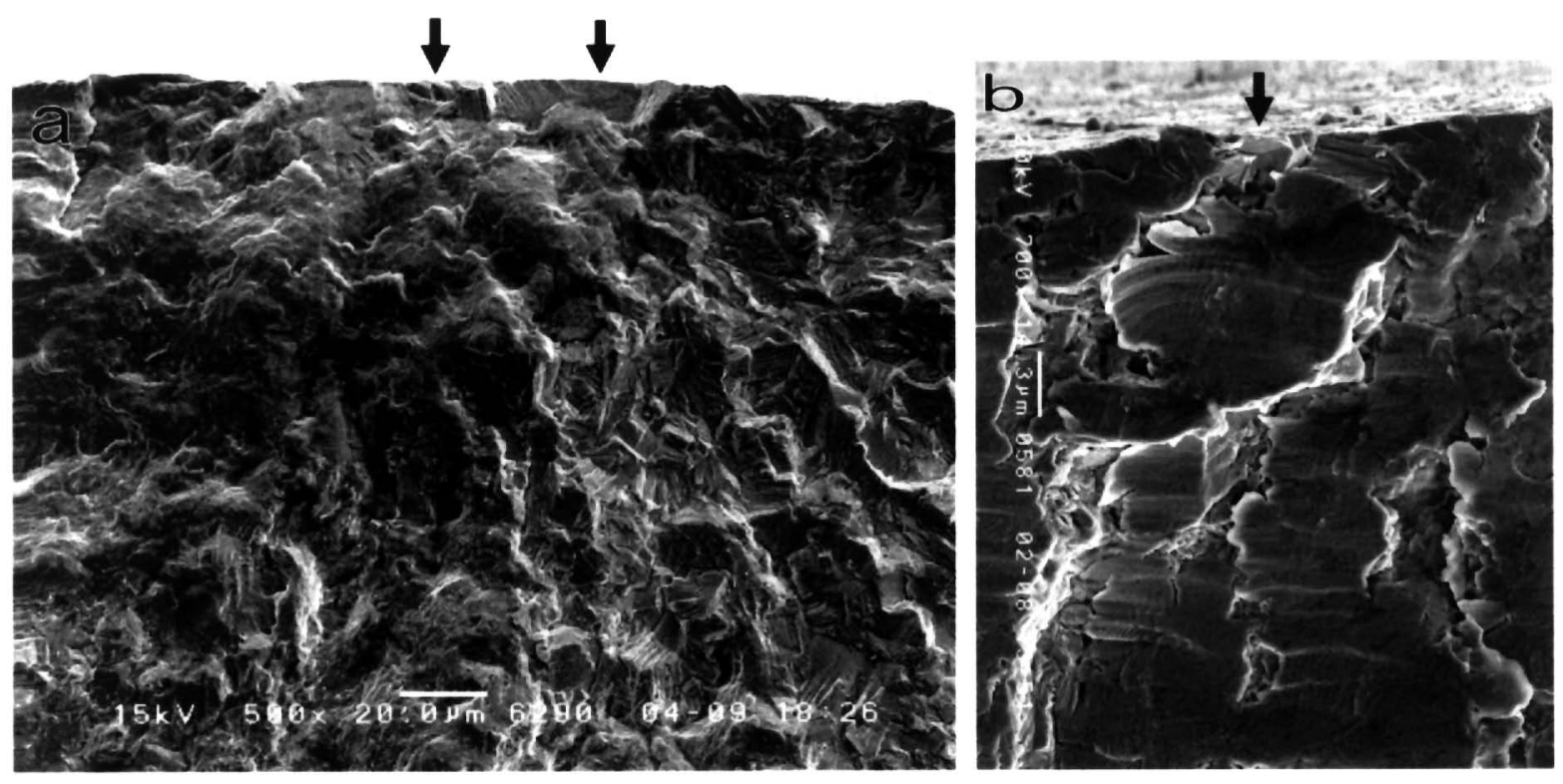

Figure 7: SEM fractographs of (a) an ultrasonically fatigued specimen $\left(\sigma_{\max }=700\right.$ $\mathrm{MPa}, N_{\mathrm{f}}=9.6 \times 10^{5}$ cycles $)$ and (b) a rotary bending fatigued specimen $\left(\sigma_{\mathrm{a}}=750 \mathrm{MPa}\right.$, $N_{\mathrm{f}}=-10^{5}$ cycles). Arrows indicate crack origins.

Figure 8 shows a sequence of SEM micrographs of a specimen ruptured after a repetition of $-5.3 \times 10^{7}$ cycles under ultrasonic frequency loading. It appears that the fatigue fracture process of Inconel 718 under ultrasonic frequency loading might be classified into four stages. The first stage is the slip bands formation and crack initiation stage. Slips that nucleated transgranularly from particular grain boundary gather to degenerate into small cracks. The effect of frequency on fatigue crack initiation was not recognized. The number of grains involved in this stage is only $1-2$ grains at each crack initiation site and the crack initiated may be $\sim 10-20 \mu \mathrm{m}$ in the surface length and up to $\sim 10 \mu \mathrm{m}$ in depth (Figure $8 \mathrm{~b}$ ).

The second stage is the stable growth stage of small cracks in the range of surface length from $\sim 20$ to 500 or longer. Cracks that initiated from slip bands extend transgranularly in this stage. 
Fractographic features in the neighbor of crack initiation area, as indicated in Figure 8b, are typical of tensile fracture. It was assumed that at ultrasonic frequency, the plastic deformation per cycle is reduced drastically because sufficient time for plastic deformation during a cycle is not available, ${ }^{[3,4]}$ in other words, the driving force at crack tips is decreased due to high frequency such that the early crack propagation is delayed (Figure 6). About $40-50 \%$ of fatigue life was spent in the second stage, which contributes largely to the strength enhancement in ultrasonic frequency fatigue.

The unstable growth of small cracks in the range of surface length beyond $\sim 500 \mu \mathrm{m}$ or longer consists of the third stage of fracture at ultrasonic fatigue, as shown in Figure 8c. The nature of fracture at this stage is apparently different from that of conventional fatigue fracture. Intense transgranular slip bands mixed with intergranularly fractured slants, implying that the fracture at this stage is brittle-dominated, mark the fracture surface. Although it is difficult to character the fracture mechanism involved in this unstable fracture process, it is believed that crack growth is accelerated due to the brittle-dominated fracture nature at this stage. The fatigue life spent in the third stage is less than $5-10 \%$.
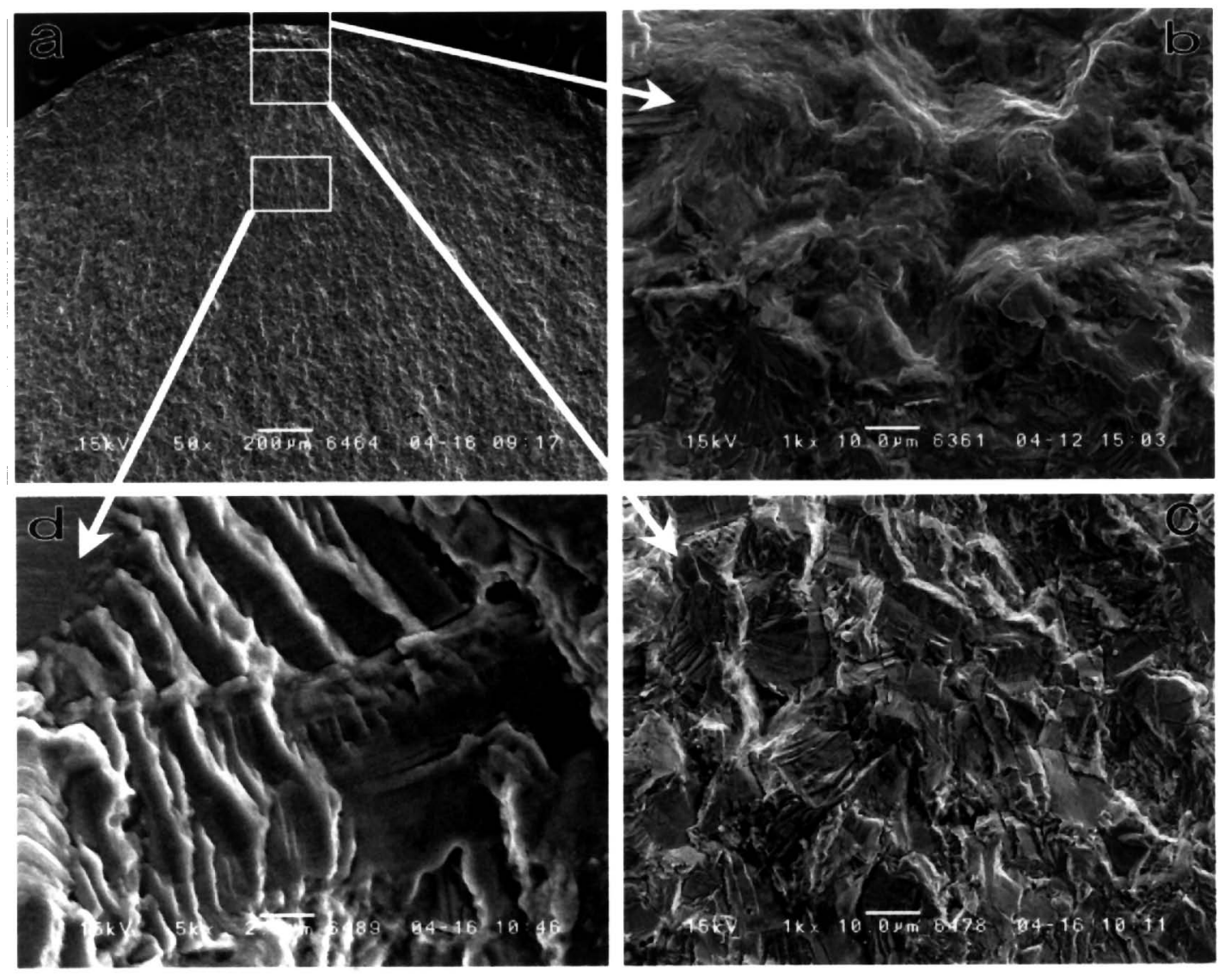

Figure 8: Fracture morphology of an ultrasonic fatigue specimen ( $\sigma_{\max }=$ $540 \mathrm{MPa}, N_{\mathrm{f}}=5.3 \times 10^{7}$ cycles). (a) Full view; (b) crack initiation area; (c) unstable crack growth zone; (d) striations observed at final fracture zone. 
Figure $8 \mathrm{~d}$ shows striations observed on the fracture surface near the final fracture area. As seen from Figure $8 \mathrm{~d}$, the spacing of striations is similar to that found in low frequency loading. However, the load at ultrasonic frequency is applied by $\sim 400$ times faster than at low frequency loading, so that cracks grow at a velocity of $\sim 400$ times faster under ultrasonic frequency than under conventional low frequency fatigue, therefore, ultrasonic fatigue has also been termed catastrophic. $^{[10]}$

\section{Conclusions}

1. Fatigue strength of Inconel 718 up to $10^{9}$ cycles was enhanced under ultrasonic frequency fatigue.

2. The initiation and early propagation of small cracks in the surface length range of $\sim 30-50$ $\mu \mathrm{m}$ were considerably delayed under ultrasonic frequency fatigue, which contributes mainly to the strength enhancement of the alloy.

3. Intense transgranular slip bands mixed with intergranularly fractured slants, implying that the nature of fracture is brittle-dominated, mark the fracture surface of ultrasonically fatigued specimens indicating that the fracture mechanism in ultrasonic fatigue is apparently different from that in conventional frequency fatigue.

\section{Acknowledgements}

One of the authors, Chen, would like to acknowledge the Japan Science Promotion Society, under grant number 11750085, and the Suzuki Foundation, under grant number 11-JYOSEII-20, for their financial supports to this project. Thanks are also due to Dr. Y. Horie for his helpful discussions. 


\section{References}

1. K. Kanazawa, and S. Nishijima, "Fatigue fracture of a low-alloy steel in the ultra-high cycle region under elevated temperature conditions," Japan Society of Materials Science, 46 (1997), 1396-1402.

2. Y. Murakami, M. Tanaka, and T. Toriyama, "Super-long life tension-compression fatigue properties of quenched and tempered $0.46 \%$ carbon steel," International Journal of Fatigue, 20 (1998), 661-667.

3. M.R. Sriraman, and R. Vasudevan, "Some aspects of the damage caused in metallic materials by ultrasonic vibrations," Materials Processing Technology, 54 (1995), 47-53.

4. D.E. MacDonald, "Ultrasonic frequency metal fatigue: A review of the investigations of the institute for the study of fatigue (fracture) and (structural) reliability," Engineering Fracture Mechanics, 8 (1976), 17-29.

5. W.P. Mason, "Internal friction and fatigue in metals at large strain amplitudes," The Journal of The Acoustical Society of America, 28 (1956), 1207-1218.

6. L.E. Willertz, "Ultrasonic fatigue," International Metals Reviews, 1980, 65-78.

7. S. Stanzl, "A new experimental method for measuring life time and crack growth of materials under multi-stage and random loadings," Ultrasonics, 19 (1981), 269-272.

8. Q.Y. Wang, and C. Bathias, "Etude de la fatigue des très longues durées de vie des métaux pour l'automobile (fonts, tôles minces, aciers à resorts)"(Technical report of CNAM, 1997).

9. G.E. Korth and G.R. Smolik, "Status report of physical and mechanical test of alloy 718 " (Report TREE-1254, EG\&G Idaho, Inc., 1978).

10. "Metal fatigue at ultrasonic frequency," Proceedings of the $1^{\text {st }}$ international symposium on high-power ultrasonics, ed. A.H. Crawford (IPC Science and Technology Press, 1972), 50-52. 